\title{
A INDÚSTRIA 4.0 E SUA APLICAÇÃO NO SETOR TÊXTIL: UMA REVISÃO DA LITERATURA BRASILEIRA
}

Leila Araújo Falani (leilayusef@gmail.com) - Universidade Federal de Santa Catarina - Departamento de Engenharia Têxtil/ Campus Blumenau

Cátia Rosana Lange de Aguiar (catia.lange@ufsc.br) - Universidade Federal de Santa Catarina Departamento de Engenharia Têxtil/ Campus Blumenau

Ana Julia Dal Forno (ana.forno@ufsc.br) - Universidade Federal de Santa Catarina - Departamento de Engenharia Têxtil/ Campus Blumenau

\section{RESUMO}

O presente trabalho objetiva descrever o resultado de uma revisão sistemática da literatura brasileira do termo indústria 4.0, aplicado ao segmento têxtil, para apresentar as áreas de aplicação, ferramentas e os benefícios. Portanto, utilizou-se a metodologia proposta por Tranfield et al. (2003), que organiza a Revisão Sistemática da Literatura para as áreas de gestão em três estágios (Planejamento, Condução e Relatório e disseminação). Assim, foram analisados seis artigos, nos quais ocorreram aplicação de oito pilares da indústria 4.0, onde a Internet das Coisas -IoT apresentou-se como a ferramenta mais aplicada, em cinco diferentes processos produtivos têxteis. Foram citados 14 benefícios dessa aplicação, sendo os mais citados: ganho de produtividade, intercomunicação de sistemas de produção e redução de perdas e refrações.

Palavras chave: indústria 4.0; têxtil; confecção; revisão sistemática da literatura. 


\section{INTRODUÇÃ̃}

Atualmente, o mercado está de passagem pela quarta revolução industrial, em que a tecnologia, digitalização e otimização dos processos vem sendo prioritários em busca por melhorias contínuas dos processos produtivos e redução de custos (ROSA et al, 2017). Diferentemente das revoluções industriais anteriores, a 4.0 reúne características de elevada velocidade, nãolinearidade, amplitude e profundidade em seu acontecimento (SCHWAB, 2017).

Entretanto, no Brasil, evidencia-se uma grande quantidade de empresas que não encontram-se alinhadas com as mudanças ocasionadas por tal revolução (ROSA et al, 2017). No segmento têxtil não é diferente, segundo a Associação Brasileira da Indústria Têxtil-ABIT (2019), mesmo o país possuindo 27,5 mil empresas formais, ser a maior cadeia têxtil completa do Ocidente, da produção das fibras, até os desfiles de moda, passando por todos os processos produtivos, tradicionalmente ainda é identificada como indústria de baixa intensidade tecnológica, podendo saltar qualitativamente em direção às categorias de amplo emprego de ciência e tecnologia, se for capaz de difundir sistemas ciberfísicos, automação modular, Internet das Coisas e de Serviços em sua manufatura (BRUNO, 2017).

Diante da importância da utilização de ferramentas da indústria 4.0 nas indústrias têxteis, esse artigo visa responder a seguinte pergunta: Como são aplicadas as ferramentas da indústria 4.0 no processo produtivo têxtil e quais os seus benefícios?

Para responder este questionamento, o trabalho objetiva descrever resultado de uma revisão sistemática da literatura brasileira com o termo indústria 4.0, aplicado ao segmento têxtil, para apresentar as áreas de aplicação da ferramenta e seus benefícios.

A estrutura do artigo inicia pela introdução, descrevendo objetivo e os temas de estudo (indústria 4.0 e segmento têxtil), na seção 2 há fundamentação teórica sobre a cadeia têxtil, explanando sua importância e atuação no Brasil, um breve histórico sobre a atuação do setor têxtil às revoluções industriais e seguidamente, definições da indústria 4.0. Na seção 3, encontra-se a metodologia utilizada para realizar a revisão bibliográfica deste estudo. Na seção 4, os resultados e discussões acerca do que foi encontrado de relevância nas publicações analisadas. Na seção 5, a conclusão sintetizando os resultados com a importância do estudo da indústria 4.0 no segmento têxtil brasileiro. Enfim, listadas as referências utilizadas. 


\section{REVISÃO BIBLIOGRÁFICA}

\subsection{Cadeia têxtil no Brasil}

Conforme Duarte (2017), a cadeia têxtil e confecção teve um importante papel na história da industrialização mundial, caracterizada desde o período pré-industrial, onde os produtos têxteis eram fabricados artesanalmente, de maneira autônoma, os artesãos tinham produção e domínio de suas ferramentas totalmente controlados. Passando por transformação na configuração do modelo de negócio aproximando a substituição do trabalho manual pelo industrial.

A indústria têxtil originou-se no Brasil no período colonial, desenvolveu-se acentuadamente no início do século XX e adquiriu maturidade na década de 40, quando chegou a ser considerada um setor industrial dinâmico de uma economia subdesenvolvida, chegou a alcançar a posição de segundo lugar na produção têxtil mundial (KON e COAN, 2009).

Segundo publicação no site da feira de referência têxtil "Go tex show" (2017), o Brasil é responsável por $2,4 \%$ da produção mundial de têxteis, ocupando a quinta posição no ranking mundial e é o quarto maior produtor de vestuário, com 2,6\% da produção mundial. Quanto a produção industrial interna, cadeia têxtil produziu aproximadamente $\mathrm{R} \$ 164,7$ bilhões em 2017 , o equivalente a 7\% do valor total da produção da indústria de transformação brasileira neste período. Ademais, gerou mais de 1,5 milhão de postos de trabalho, equivalendo a $18,7 \%$ do total de trabalhadores alocados na produção industrial em 2017, enfatizando que além da sua grande relevância econômica, é um segmento de intenso impacto social (IEMI, 2018).

A cadeia têxtil e confecção pode identificar-se através do quadro 1, onde são apresentados os principais processos produtivos com breves descrições e aplicabilidade. 
QUADRO 1 - Cadeia têxtil e seus processos.

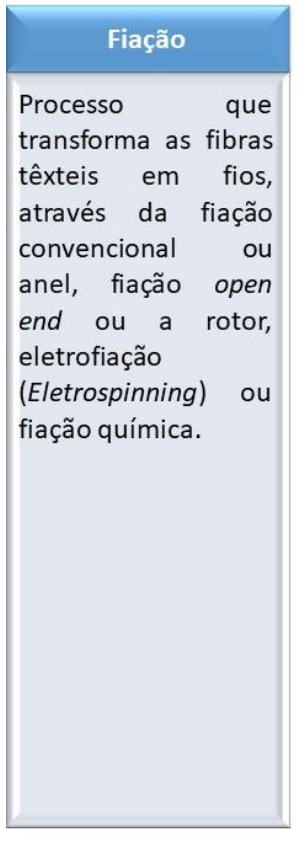

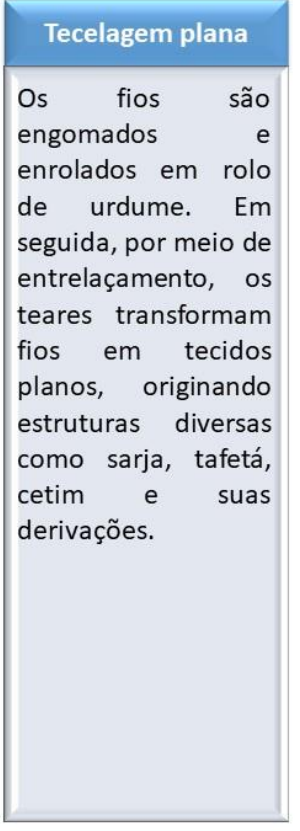

\begin{tabular}{|c|}
\hline Malharia \\
\hline $\begin{array}{l}\text { A formação de } \\
\text { tecidos de malha } \\
\text { pode ser por trama, } \\
\text { através dos métodos } \\
\text { de entrelaçamento } \\
\text { de malhas na } \\
\text { direção transversal, } \\
\text { com um ou mais } \\
\text { fios, que podem ser } \\
\text { dispostas em sentido } \\
\text { lateral ou circular. E } \\
\text { por urdume, através } \\
\text { do método de } \\
\text { entrelaçamento de } \\
\text { malhas em sentido } \\
\text { longitudinal com } \\
\text { numerosos fios. }\end{array}$ \\
\hline
\end{tabular}

\begin{tabular}{|c|}
\hline Beneficiamento \\
\hline 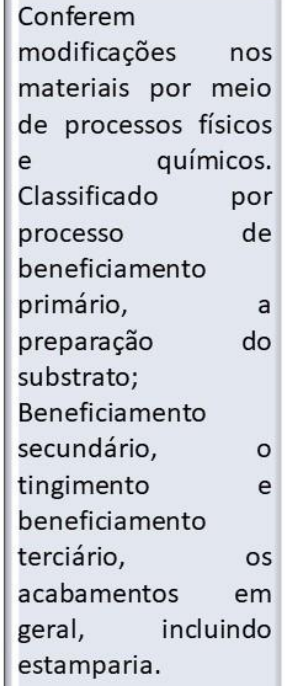 \\
\hline
\end{tabular}

\begin{tabular}{|c|}
\hline Confecção \\
\hline $\begin{array}{l}\text { Inicia no enfesto que } \\
\text { é o processo que } \\
\text { otimiza e organiza } \\
\text { em camadas o } \\
\text { substrato, de acordo } \\
\text { coma quantidade de } \\
\text { peças a serem } \\
\text { produzidas, em } \\
\text { seguida estas } \\
\text { camadas serão } \\
\text { cortadas (manual ou } \\
\text { automaticamente) } \\
\text { direcionando para a } \\
\text { costura, processo } \\
\text { que une os } \\
\text { componentes } \\
\text { previamente } \\
\text { cortados a fim de } \\
\text { confeccionar a peça } \\
\text { desejada. }\end{array}$ \\
\hline
\end{tabular}

No histórico do setor têxtil, pode-se ressaltar os avanços tecnológicos como fator estratégico para gerar mudanças que contribuíram para o aprimoramento de técnicas, ferramentas e utilização de novos insumos. Portanto, antes de referenciar as características da indústria 4.0, é necessário entender um pouco da história da revolução industrial que norteia os dias atuais.

\subsection{Revoluções industriais no segmento têxtil}

Segundo Sakurai e Zuchi (2018), a indústria têxtil foi pioneira em utilizar a nova tecnologia da máquina a vapor durante a Primeira Revolução Industrial. Posteriormente, outros segmentos utilizaram meios de automação de processos, assim, inseriram máquinas em sua cadeia produtiva, portanto, a indústria têxtil tornou-se símbolo na excelência de produção.

Na Primeira Revolução Industrial, houve diversas inovações no segmento, como a criação de lançadeiras para facilitar a passagem do fio no tear, criação de máquina hidráulica de fiar, para produção de fios, ambos processos, antes eram realizados manualmente. Joseph-Marie Jacquard combinou mecanismos já existentes para desenvolver o Tear Jacquard e também foi o inventor dos cartões perfurados que, após, tornaram-se base para os cartões de memória usados nos 
computadores (MCNEIL, 2002).

A Segunda Revolução Industrial foi marcada pelo aprimoramento de tecnologias, pesquisas científicas dos conhecimentos práticos obtidos na primeira revolução, aumento na produtividade e introdução de novas fontes de energia na indústria têxtil (DUARTE, 2017). Também foi patenteado o primeiro tear circular com estrutura ribana, muito utilizada em suéteres, golas e punhos. Apesar de ter sido inventada anteriormente, Isaac Singer patenteou a primeira máquina de costura doméstica, que mudou significativamente o consumo e produção de roupas (MCNEIL, 2002).

Na Terceira Revolução Industrial, explorou-se o uso da eletrônica e tecnologia da informação para a automação produtiva, acarretando renovação no processo econômico, político e social, com grande dinamismo e alta complexidade. Segundo Duarte (2007), algumas soluções tecnológicas na indústria têxtil para atuar com customização em massa, como escaneamento, modelagem 3D e estamparia digital estão sendo gradualmente adotadas pela indústria têxtil.

Kagermann, et al (2013) relata que as primeiras três revoluções industriais são oriundas da mecanização, eletricidade e tecnologia da informação. Diante disso, a expressão indústria 4.0 começou então a ser utilizada para designar uma quarta fase industrial baseada em produtos e processos resultantes das mudanças tecnológicas atuais (DE OLIVEIRA, 2017).

Bruno (2017) descreve o futuro do segmento têxtil com mini fábricas automatizadas, modulares, móveis e sustentáveis que serão acopladas a sistemas virtuais da criação e produção, reconfigurando a atual estruturação industrial. Quanto aos produtos, a aplicação de biotecnologias e de novos materiais expandirá a demanda por produtos têxteis inteligentes e funcionais, acrescendo exponencialmente a diversidade e a intensidade tecnológica de fios, tecidos, aviamentos e produtos auxiliares necessários para atender demandas de consumo.

\subsection{Indústria 4.0}

Antes da denominar quarta revolução industrial, diferentes tecnologias já eram empregadas, individualmente ou conectadas com outras, objetivando melhorar processos industriais (MAESTRI, 2018).

Schwab (2017) ressalta que o que torna a Quarta Revolução Industrial fundamentalmente 
diferente das anteriores é que seu escopo é muito mais amplo, não se resume apenas a sistemas e máquinas inteligentes e conectadas, novas descobertas ocorrem simultaneamente em áreas desde sequenciamento genético até a nanotecnologia, das energias renováveis à computação quântica.

Conforme Schwab e Davis (2019), as tecnologias emergentes da indústria 4.0 são construídas sobre o conhecimento e os sistemas das revoluções industriais anteriores, em particular, sobre recursos digitais da terceira Revolução Industrial. Diante disso, Rüßmann et al. (2015), classificam a indústria 4.0 em nove pilares de desenvolvimento tecnológico aplicáveis no campo industrial, apresentado na Figura 1.

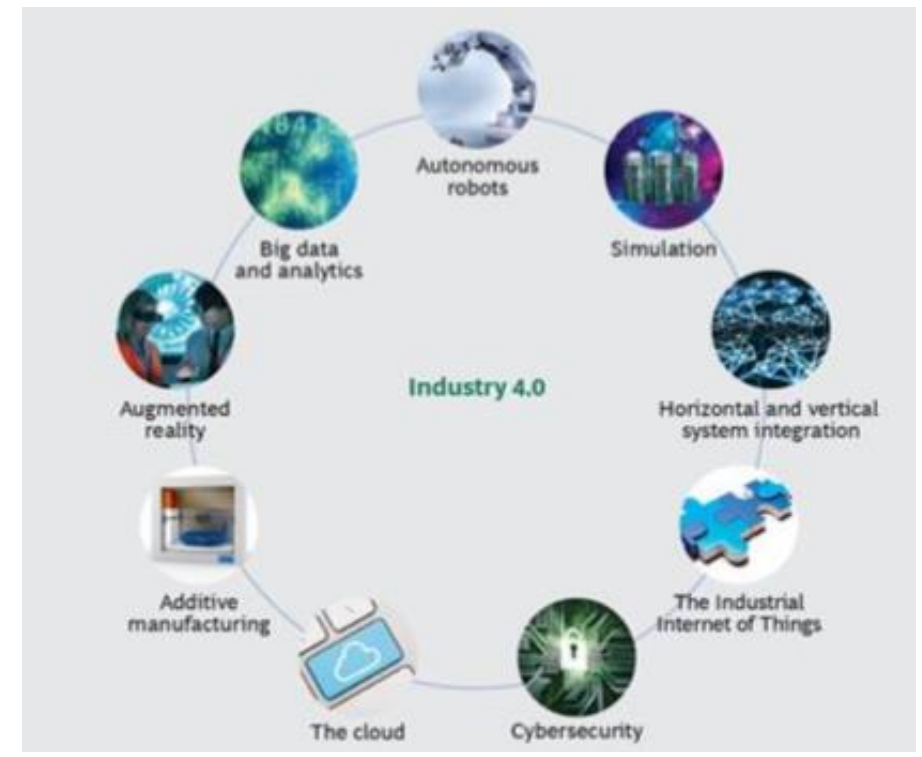

FIGURA 1 - Pilares tecnológicos da indústria 4.0. Fonte: Rüßmann et al. (2015).

Conforme Rüßmann et al. (2015), os robôs autônomos, tornarão mais autônomos, flexíveis e cooperativos, possibilitando completar determinada tarefa de forma precisa e inteligente dentro do tempo pré-determinado, focando na segurança, flexibilidade, versatilidade e colaboração (VAIDYA et al., 2018).

A simulação consiste na reprodução das operações de fabricação de um sistema do mundo real, que pode incluir máquinas, produtos e seres humanos (MOKTADIR et al., 2018; VAIDYA et al., 2018). É um aspecto relevante pois possui elevados investimentos e baixo erro de tolerância. 
Conceitos de máquinas, roupas e fábricas virtuais surgem em projetos como os das mini fábricas (BRUNO, 2017).

Integração de sistemas vertical e horizontal consiste na integração digital completa e automação de fabricação de processos na dimensão vertical e horizontal, implicando em uma automatização da comunicação e da cooperação ao longo de processos produtivos (VAIDYA et al., 2018).

Bruno (2017) conceitua Internet das Coisas (IoT ou IdC) como um ecossistema com bilhões de dispositivos no qual sensores de radiofrequência, atuadores e celulares interagem entre si e cooperam com componentes e dispositivos vizinhos para atingirem objetivos comuns. Trata-se então, da relação entre coisas (produtos, serviços, lugares) e pessoas, por meio de plataformas e tecnologias conectadas (SCHWAB, 2017).

Com a necessidade de proteger os sistemas industriais críticos e linhas de fabricação, aumenta significativamente a necessidade de segurança cibernética, resultado à indústria comunicações seguras e confiáveis, bem como gerenciamento sofisticado de identidade e acesso de máquinas, onde usuários são essenciais (RÜßMANN et al., 2015). Os Sistemas Cibernético-Físico (CPS) consistem na integração da computação, redes de comunicação e processos físicos. Ao contrário dos sistemas tradicionais, o objetivo do CPS é monitorar e controlar vários dispositivos, máquinas e equipamentos de um processo produtivo através de rede, permitindo a comunicação de dispositivos físicos com o sistema cibernético e vice-versa (PISCHING et al., 2015).

Com a indústria 4.0, as empresas precisam elevar compartilhamentos de dados por meio dos sites e steakholders, ou seja, para efetividade da informação, é necessário, alcançar os tempos de reação em milissegundos ou até mais rápido, portanto, utiliza-se computação em nuvem, que consiste em máquinas virtuais on-demand acopladas a serviços de software capazes de enviar uma gama de serviços de maneira confiável e segura para múltiplos dispositivos, garantindo a computação móvel. Os principais serviços em nuvem são: Big-data, e-commerce, computação social e móvel, inteligência de negócios, logística e ERP (RÜßMANN et al., 2015; BRUNO, 2017).

Manufatura aditiva objetiva tornar mais rápido e mais barato o sistema de produção. Beneficia a produção industrial, pois confecciona pequena quantidade de produtos personalizados com 
aperfeiçoamento de design. A fabricação de produtos aditivos também auxilia na logística e controle de estoque (MOKTADIR et al., 2018).

Segundo Vaidya et al. (2018), a indústria pode usar a realidade aumentada para fornecer aos funcionários informações em tempo real, melhorando a tomada de decisões e os procedimentos de trabalho. Os trabalhadores podem receber instruções ao realizar manutenções.

Rüßmann et al. (2015) afirma que a possibilidade da análise dos dados otimiza a qualidade, economiza energia e melhora a eficiência de equipamentos e sistemas produtivos. No contexto da indústria 4.0, utilizar tecnologia big data, auxilia na abordagem para captura, análise e gerenciamento de informações (SAKURAI e ZUCHI, 2018).

\section{METODOLOGIA}

O processo de revisão da literatura é um instrumento de grande relevância, utilizado para gerenciar a diversidade de conhecimento para uma investigação acadêmica específica, que tem como objetivo em sua maioria das vezes, mapear e avaliar o território intelectual existente e especificar uma questão importante para desenvolver o corpo de conhecimento existente (TRANFIELD et al. 2003).

Neste estudo, utilizou-se a metodologia de Revisão Sistemática da Literatura para as áreas de gestão proposta por Tranfield et al. (2003), que são organizados em três estágios, conforme Figura 2. 


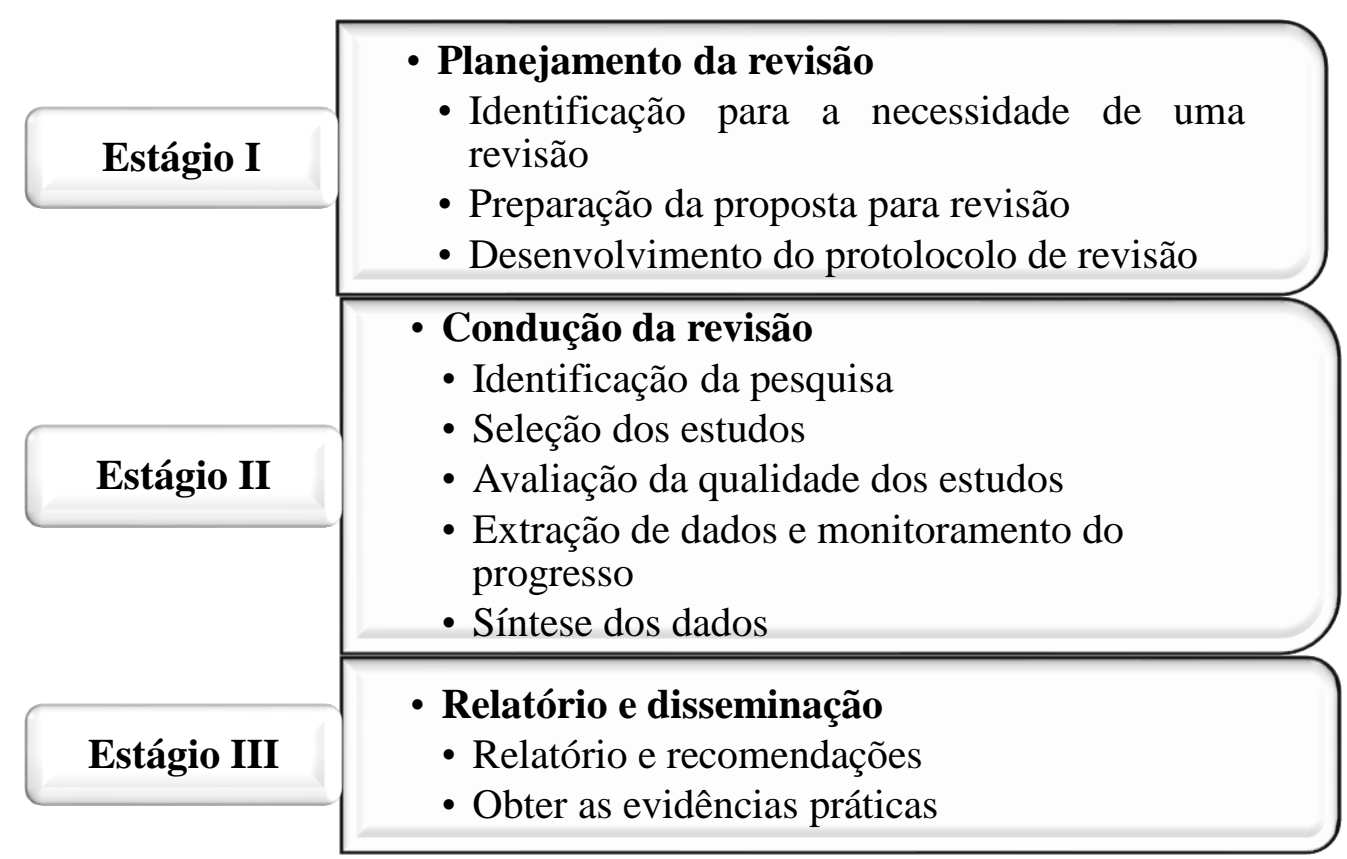

FIGURA 2 - Estágios da revisão sistemática da literatura. Fonte: Elaborado a partir de Tranfield et al. (2003).

\section{a) Estágio I - Planejamento da revisão}

O objetivo desta revisão é identificar o que está sendo estudado acerca das ferramentas da indústria 4.0 no processo produtivo têxtil. Assim, a presente pesquisa destacou as perguntas:

- Quais as principais ferramentas da indústria 4.0 são aplicadas no segmento têxtil?

- Em que etapa do processo produtivo aplica-se as ferramentas da indústria 4.0?

- Quais os benefícios gerados?

Para Tranfield et al. (2003), o objetivo da revisão sistemática é produzir um protocolo que não compromete a capacidade criativa do pesquisador no processo de revisão de literatura, garantindo que as revisões sejam menos amplas na linha de pesquisa do que as revisões narrativas mais tradicionais. Portanto, a base de dados utilizada para a pesquisa foi o Google Scholar, já que o objetivo é analisar a literatura brasileira sobre o tema, foi selecionado apenas o idioma português do Brasil, descartando o português de Portugal. O período limitado de 2011 até abril de 2019, pois o termo “indústria 4.0" surgiu em 2011 através de iniciativas estratégicas do governo Alemão para consolidar o país como líder em tecnologia e fortalecer sua competitividade global (KAGERMANN et al., 2013). 


\section{b) Estágio II - Condução da revisão}

De acordo com Tranfield et al. (2003), uma busca sistemática começa com a identificação de palavras-chave. Entretanto, as palavras-chave foram "Industria 4.0" e "Têxtil" que geraram 151 publicações entre teses, dissertações, artigos e trabalho de conclusão de curso. As citações e patentes foram excluídas.

Para critério de qualidade, foram selecionados artigos em que os dois temas eram relacionados com relevância na pesquisa. A partir da aplicação da estratégia de busca e aprimoramento do resultado, a pesquisa seguiu as seguintes etapas:

1. Leitura do título, resumo e palavras-chaves utilizadas, resultando em 28 publicações;

2. Leitura da introdução e conclusão, na qual foram selecionados 10 artigos a partir do critério de aceitação, a publicação deveria correlacionar a aplicação de ferramentas da indústria 4.0 na área têxtil e de confecção.

3. Leitura de método, discussão e resultados, em que resultou em 6 publicações, desconsiderando assim, publicações com aplicação em áreas correlatas apenas ao design de moda;

\section{c) Estágio III - Relatório e disseminação}

A etapa final é a apresentação dos resultados e a análise dos estudos selecionados. Primeiramente, uma descrição do que foi encontrado nas 6 publicações selecionadas em relação a utilização das ferramentas da indústria 4.0, etapa do processo têxtil, bem como seus benefícios gerados, e por fim uma análise do cruzamento das informações extraídas dos estudos.

\section{RESULTADOS E DISCUSSÕES}

Foram analisados seis artigos que descreviam a aplicação de ferramentas tecnológicas da indústria 4.0 no processo têxtil. Identificou-se aplicação das ferramentas: Internet das Coisas IoT, manufatura aditiva, big data, simulações, computação em nuvem, Sistemas CibernéticoFísico - CPS e robôs autônomos, nos setores têxteis de fiação, malharia, beneficiamento e confecção. 
O trabalho de Duarte (2017) teve em seu escopo propor um modelo de referência para a integração entre ferramentas de avaliação do ciclo de vida e indústria 4.0 na produção de camisetas. Ela afirma que a avaliação de ciclo de vida do produto se beneficiaria dos CPS, da informação vinda em tempo real da internet das coisas e do histórico de informações do Big Data de forma a recalcular-se ou atualizar-se simultaneamente para cada estágio de produção: fiação, malharia e confecção.

O artigo de Conceição e Santos (2017) apresenta novas perspectivas para o processo de desenvolvimento de roupas e acessórios do vestuário com a aplicação de tecnologias digitais de produção, com enfoque nas soluções em manufatura aditiva. Os autores afirmam que a utilização desta tecnologia tem mostrado rápido crescimento e com a utilização das impressoras 3D vem ganhando ascensão, inclusive no Brasil.

Maestri (2018) aplicou um questionário que foi possível diagnosticar o conhecimento e interesse de profissionais do setor e alunos de engenharia quanto ao tema indústria 4.0, os resultados foram apresentados graficamente e indicaram baixos percentuais de conhecimento das tecnologias. $\mathrm{O}$ trabalho teve como objetivo propor sugestões inovadoras para os setores de fiação, estamparia, confecção e malharia, além de desenvolver um modelo de malharia 4.0.

Piccinini e Carvalhinha (2017) em seu artigo, apresentaram conceitos relacionados à Indústria 4.0 e suas possíveis implicações para a organização do trabalho. Explanam a metodologia utilizada pelas empresas estudadas que possuem a presença de teares retilíneos dentro da loja, confeccionando diretamente o vestuário, eliminando etapas de corte, costura e acabamentos. Isso é permissível diante da utilização da tecnologia de manufatura aditiva e simulações de modelagem, permitindo ao cliente não apenas customizar/desenvolver o produto, mas também presenciar sua produção e receber o produto imediatamente condizente com suas medidas. As autoras ressaltam que as aplicações das tecnologias ainda estão distantes de soluções robustas, não havendo indicações claras se o resultado em termos de geração de riqueza e empregos, por exemplo, será alcançado.

Círico (2018) objetivou desenvolve um sistema de manutenção autônomo, reduzindo tempo de espera dos equipamentos de costura, minimizando perdas produtivas do processo de uma empresa têxtil. A sua proposta de melhoria consiste que a cada troca de aviamento a ser costurado, com resultado satisfatório devido ao fato de ter sido ampliada a possibilidade de o 
próprio operador efetuar o setup de seu equipamento definitivamente sem nenhuma interferência mecânica.

O trabalho de Maestri et al. (2019) foi realizado com base no trabalho de Maestri (2018), onde também teve no escopo propor sugestões inovadoras aos setores de fiação, estamparia e confecção, com base nas tecnologias envolvidas na Indústria 4.0 com utilização de robôs autônomos e utilização da IoT.

Os benefícios encontrados foram: Possibilidade de customização em massa (DUARTE; CONCEIÇÃO E SANTOS, 2017); Agilidade em lançamento de novos produtos (CONCEIÇÃO E SANTOS; PICCININI E CARVALHINHA, 2017); Automatização de processos (MAESTRI; CÍRICO, 2018; MAESTRI et al., 2019); Intercomunicação de sistema de produção (PICCININI E CARVALHINHA, 2017; MAESTRI; CÍRICO, 2018; MAESTRI et al., 2019); Redução de perdas e refrações (CONCEIÇÃO E SANTOS, 2017; MAESTRI; CÍRICO, 2018; MAESTRI et al., 2019); Ganho de produtividade (CONCEIÇÃO E SANTOS; PICCININI E CARVALHINHA, 2017; MAESTRI; CÍRICO, 2018; MAESTRI et al., 2019); Menor setup (CÍRICO, 2018); Facilidade na busca de soluções alternativas ou novas tecnologias (DUARTE, 2017); Rapidez na resolução de problemas (DUARTE, 2017; CÍRICO, 2018); Controle e monitoramento das atividades industriais (DUARTE, 2017; MAESTRI; CÍRICO, 2018; MAESTRI et al., 2019); Gerar padrões de qualidade (DUARTE, 2017; MAESTRI, 2018); Descentralização da produção (DUARTE, 2017); Economicamente viável (CONCEIÇÃO E SANTOS, 2017; MAESTRI; CÍRICO, 2018) e melhora da ergonomia (MAESTRI, 2018; MAESTRI et al., 2019).

A representação da análise dos artigos foi apresentada na tabela 2 para uma melhor visualização das informações extraídas de cada estudo, destacando-se os benefícios mais citados. 


\begin{tabular}{|c|c|c|c|c|c|c|c|}
\hline & Autores & Duarte (2017) & $\begin{array}{c}\text { Conceição e } \\
\text { Santos (2017) }\end{array}$ & Maestri (2018) & \begin{tabular}{|c|} 
Piccinini e \\
Carvalhinha \\
$(2017)$ \\
\end{tabular} & Círico (2018) & $\begin{array}{c}\text { Maestri et al . } \\
\text { (2019) }\end{array}$ \\
\hline \multicolumn{2}{|c|}{ Ferramenta (s) tecnológica aplicada } & $\begin{array}{c}\text { CPS; Big } \\
\text { data e IoT }\end{array}$ & $\begin{array}{l}\text { Manufatura } \\
\text { aditiva }\end{array}$ & $\begin{array}{c}\text { Robôs } \\
\text { autônomos e } \\
\text { IoT } \\
\end{array}$ & \begin{tabular}{|c|} 
Manufatura \\
aditiva e \\
simulação \\
\end{tabular} & $\begin{array}{c}\text { Computação } \\
\text { em nuvem }\end{array}$ & $\begin{array}{c}\text { Robôs } \\
\text { autônomos e } \\
\text { IoT } \\
\end{array}$ \\
\hline \multicolumn{2}{|c|}{ Etapa (s) do processo produtivo têxtil } & $\begin{array}{c}\text { Fiação, } \\
\text { malharia e } \\
\text { confecção }\end{array}$ & Confecção & \begin{tabular}{|c|} 
Fiação, \\
malharia, \\
beneficiamento \\
e confecção
\end{tabular} & \begin{tabular}{|c|} 
Malharia e \\
confecção
\end{tabular} & Confecção & $\begin{array}{c}\text { Fiação, } \\
\text { beneficiament } \\
\text { o e confecção }\end{array}$ \\
\hline \multicolumn{2}{|r|}{ Local de origem do trabalho } & São Paulo & $\begin{array}{l}\text { Rio de } \\
\text { Janeiro }\end{array}$ & Santa Catarina & São Paulo & $\begin{array}{c}\text { Santa } \\
\text { Catarina } \\
\end{array}$ & $\begin{array}{c}\text { Santa } \\
\text { Catarina } \\
\end{array}$ \\
\hline \multirow{14}{*}{ 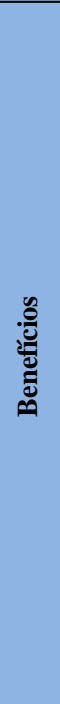 } & Customização em massa & $\mathbf{X}$ & $\mathbf{X}$ & & & & \\
\hline & $\begin{array}{|lll|}\text { Agilidade em lançamentos de } \\
\text { novos produtos }\end{array}$ & & $\mathbf{x}$ & & $\mathbf{X}$ & & \\
\hline & $\begin{array}{l}\text { Intercomunicação entre sistemas } \\
\text { de produção }\end{array}$ & & & $\mathbf{X}$ & $\mathbf{X}$ & $\mathbf{X}$ & $\mathbf{x}$ \\
\hline & \begin{tabular}{|l|} 
Redução de perdas e refrações \\
\end{tabular} & & $\mathbf{X}$ & $\mathbf{X}$ & & $\mathbf{X}$ & $\mathbf{X}$ \\
\hline & Ganho de produtividade & & $\mathbf{X}$ & $\mathbf{X}$ & $\mathbf{X}$ & $\mathbf{X}$ & $\mathbf{X}$ \\
\hline & Menor set up & & & & & $\mathbf{X}$ & \\
\hline & \begin{tabular}{|l|} 
Facilidade na busca de soluções \\
alternativas ou novas tecnologias
\end{tabular} & $\mathbf{X}$ & & & & & \\
\hline & Rapidez na solução dos problemas & $\mathbf{X}$ & & & & $\mathbf{X}$ & \\
\hline & \begin{tabular}{|l|} 
Controle e monitoramento das \\
atividades industriais
\end{tabular} & $\mathbf{X}$ & & $\mathbf{X}$ & & $\mathbf{X}$ & $\mathbf{X}$ \\
\hline & \begin{tabular}{|l|} 
Gerar padrões de qualidade \\
\end{tabular} & $\mathbf{X}$ & & $\mathbf{X}$ & & & \\
\hline & Descentralização da produção & $\mathbf{X}$ & & & & & \\
\hline & Viável economicamente & & $\mathbf{X}$ & $\mathbf{X}$ & & $\mathbf{X}$ & \\
\hline & Automatização dos processos & & & $\mathbf{X}$ & & $\mathbf{X}$ & $\mathbf{X}$ \\
\hline & Melhoria da ergonomia & & & $\mathbf{X}$ & & & $\mathbf{X}$ \\
\hline
\end{tabular}

TABELA 2 - Benefícios da aplicação das ferramentas da indústria 4.0 e os setores de sua aplicação.

\section{CONSIDERAÇÕES FINAIS}

Este artigo descreveu o resultado de uma revisão sistemática da literatura brasileira com o intuito de identificar as tecnologias da indústria 4.0 aplicadas ao segmento têxtil, para apresentar as áreas de aplicação deste conceito e os benefícios identificados pelas seis publicações avaliadas.

Dentre os trabalhos analisados, foi unanime a aplicação de ferramentas da indústria 4.0 no setor de confecção, corroborando com a pesquisa realizada pela ABIT (2019) em maio deste ano, aplicada aos empresários do setor, identificando suas percepções da atualidade e perspectivas dos principais indicadores econômicos do ramo têxtil, onde $25 \%$ das empresas são consideradas preponderantemente do segmento têxtil, liderando o ranking dos setores.

Outro fato relevante nessa pesquisa da ABIT (2019), foi o ranking dos estados que mais se concentram as atividades de suas empresas. Em primeiro lugar foi São Paulo com $40 \%$, em 
seguida o estado do Rio Grande do Sul com $21 \%$ e em terceiro o estado de Santa Catarina, com a parcela de $12 \%$, podendo correlacionar com os estados das publicações que se concentraram basicamente em São Paulo e Santa Catarina, com exceção de Conceição e Santos (2017) do estado do Rio de Janeiro.

Apesar do termo indústria 4.0 ter aparecido em publicações internacionais desde 2011, o estudo desta temática vem crescendo no Brasil somente a partir de 2017, sendo ainda muito teórico. Conforme somente Duarte (2017) e Círico (2018) realizaram um estudo de caso, utilizando na prática as tecnologias em suas áreas de atuação.

Duarte (2017) afirma que a cadeia têxtil e de confecção no Brasil se encontra na transição para a Terceira Revolução Industrial, com a digitalização de componentes e processos produtivos. Piccinini e Carvalhinha (2017) complementam que apesar de vir conduzindo iniciativas relacionadas à Indústria 4.0, o país ainda é um ator fraco do ponto de vista industrial e de integração às cadeias globais, portanto pode se posicionar mais como consumidor dos desenvolvimentos tecnológicos, do que como líder no mercado.

\section{REFERÊNCIAS}

ASSOCIAÇÃO BRASILEIRA DA INDÚSTRIA TÊXTIL. Pesquisa de Conjuntura ABIT. 2019. Disponível em: https://www.abit.org.br/cont/dados-economia. Acesso em: 5 jun. 2019.

BRUNO, F. da S. A Quarta Revolução Industrial do setor têxtil e de confecção: a visão de futuro para 2030. São Paulo: Estação das Letras e Cores, 2017.

CÍRICO, Elvis. Desenvolvimento de uma matriz de centralização para aumento de produtividade em uma empresa têxtil. Jaraguá do Sul. Trabalho de Conclusão de Curso (Fabricação Mecânica) - INSTITUTO FEDERAL DE EDUCAÇÃO, CIÊNCIA E TECNOLOGIA DE SANTA CATARINA, 2018.

CONCEIÇÃO, M. E. de J.; SANTOS, J. R. L. dos. Remodelando o Design do Vestuário com tecnologias digitais de produção. Revista Triades, 2017, 6.1.

DE OLIVEIRA, I. R. Indústria 4.0: um novo paradigma técnico-económico?. Portugal, 2017. Dissertação (Economia e gestão da inovação) - Universidade do Porto.

DUARTE, ADRIANA YUMI SATO. Proposta de integração entre ferramentas de avaliação de ciclo de vida do produto e Indústria 4.0 (Industrie 4.0): estudo de caso da indústria têxtil e de confecção brasileira. Campinas, 2017. Tese (Engenharia Mecânica) - UNIVERSIDADE ESTADUAL DE CAMPINAS.

INSTITUTO DE ESTUDOS E MARKETING INDUSTRIAL. A geração de empregos na indústria têxtil e confeccionista volta a crescer, mesmo com o fechamento de empresas. IEMI. São Paulo, 2018. Disponível em: http://www.iemi.com.br/a-geracao-de-empregos-na-industria-textil-e-confeccionista-volta-a-crescer-mesmocom-o-fechamento-de-empresas/. Acesso em: 28 mai. 2019. 
KAGERMANN, Henning et al. Recommendations for implementing the strategic initiative INDUSTRIE 4.0: Securing the future of German manufacturing industry; final report of the Industrie 4.0 Working Group. Forschungsunion, 2013.

KON, Anita; COAN, Durval Calegari. Transformações da Indústria Têxtil Brasileira: A Transição para a Modernização. Revista de Economia Mackenzie, São Paulo, v. 3, n. 3, p. 11-34, 2005.

MAESTRI, G. Indústria 4.0 no Setor Têxtil: Diagnóstico Atual, Desafios e Oportunidades para o Futuro Digital. Blumenau. Trabalho de Conclusão de Curso (Engenharia têxtil) - UNIVERSIDADE FEDERAL DE SANTA CATARINA, 2018.

MAESTRI, G.; OLIVEIRA, F. R.; STEFFENS, F. Impulso das tecnologias 4.0 na indústria têxtil. In: GESTÃo da Produção em Foco. Poisson, v. 31, 2019. cap. 7, p. 68-76.

MERCADO: Panorama do setor têxtil e de confecção. Go tex show. 2017. Disponível em: http://gotexshow.com.br/mercado/. Acesso em: 28 mai. 2019.

MCNEIL, Ian. An encyclopedia of the history of technology. Routledge, 2002.

MOKTADIR, M. A. et al. Assessing challenges for implementing Industry 4.0: Implications for process safety and environmental protection. Process Safety and Environmental Protection, v. 117, 2018. p. 730-741.

PICCININI, L.; CARVALHINHA, M. P. da. A INDÚSTRIA 4.0 E OS NOVOS PARADIGMAS DA RELAÇÃO ENTRE PRODUÇÃ̃O E CONSUMO: IMPLICAÇÕES PARA A ORGANIZAÇÃO DO TRABALHO NA INDÚSTRIA DO VESTUÁRIO. Bauru, 2017.

PISCHING, Marcos A., et al. Service composition in the cloud-based manufacturing focused on the industry 4.0. In: Doctoral Conference on Computing, Electrical and Industrial Systems, 2015. p. 65-72.

ROSA, A. L. T. et al. LEAN MANUFACTURING: UMA ABORDAGEM DA APLICAÇÃO DA FERRAMENTA SMED EM INDÚSTRIA RUMO Á MANUFATURA 4.0. Joinville, 2017.

RÜßMANN, M. et al. Industry 4.0: The future of productivity and growth in manufacturing industries. Boston Consulting Group, 2015, 9.1: 54-89.

SAKURAI, R.; ZUCHI, J. D. AS REVOLUÇÕES INDUSTRIAIS ATÉ A INDUSTRIA 4.0. Revista Interface Tecnológica, 2018, 15.2: 480-491.

SCHWAB, K. The fourth industrial revolution. Currency, 2017.

SCHWAB, K.; DAVIS, N. Aplicando a quarta revolução industrial. EDIPRO, 2019.

TRANFIELD, D.; DENYER, D.; SMART, P. Towards a Methodology for Developing Evidence-Informed Management Knowledge Means of Systematic Review. British Journal of Management, 14(3), 207-222, 2003.

VAIDYA, S.; AMBAD, P.; BHOSLE, S. Industry 4.0-a glimpse. Procedia Manufacturing, 2018, 20: 233-238. 